\title{
EKSPLORASI ECO PRINTING DAUN LANANG DAN PEWARNAAN ALAM KAYU TEGERAN PADA KAIN RAYON SEB AGAI POTENSI MATERIAL FASHION SUSTAINABLE
}

\author{
Aulia Wara Arimbi Putri ${ }^{1 *}$, Jesslyn Ivana Kristi2 ${ }^{*}$ \\ Program Studi D-3 Seni Rupa dan Desain Fakultas Seni Rupa dan Desain \\ Universitas Kristen Maranatha \\ Jl. Surya Sumantri No. 65, Sukawarna, Kec. Sukajadi, Kota Bandung, Kode Pos 40164 \\ Jawa Barat. Indonesia \\ Email:aulia.fiberart@gmail.com, jesslyn220@gmail.com
}

\begin{abstract}
Abstrak
Perkembang an industri tekstil dan fashion yang sangat pesat beberapa tahun ini, khususnya di Indonesia, dirasakan turut menimbulkan berbagai dampak yang kurang baik terhadap lingkungan, salah satunya diakibatkan dari limbah yang dihasilkan dari proses produksinya. Pemberdayaan produk yang berkelanjutan adalah suatu cara penanggulangan yang baik dalam penanganan kerusakan yang ditimbulkan sekaligus menjaga keles tarian alamny a. Produk fashion yang memiliki konsep sustainable atau eco design dengan pemanfaatan hasil alam, merupakan konsep yang dimasa kini kian marak diusung oleh para pelaku industritekstildan fashion besarhing ga rumahan. Teknik pencelupan wama alam dan eco printing adalah cara yang dapat digunakan untuk menggantikan zat kimia dalam proses pewarnaan dan pemberian motif pada material kain secara alami yang berasal dari banyak variasi ekstrak tumbuhan. Proses eksperimen ekstrak kayu tegeran sebagailarutan pewarna material kain utama dan kandungan tanin pada daun lanang sebagai motif serta didukung dengan mordan tunjung dan fiksator tawas, merupakan kombinasi yang difokuskan sebagai penelitian terhadap variasi efek yang ditimbulkan ketika diaplikasikan pada kain rayon yang mulai digunakan sebagai material pokok pengg anti polyester murni dan alternatif kain yang lebih dapat dijangkau oleh masyarakat di Indonesia dan juga mulai diperkenalkan sebagai jenis kain utama di Indonesia, yang semuanya dimanfaatkan sebagai media material dan bahan untuk memproduksi sebuah produk fashion yang ramah lingkungan.
\end{abstract}

Kata Kunci: eco, fashion, printing, rayon, sustainable

\begin{abstract}
The development of the textile and fashion industry which is growing rapidly in recentyears, especially in Indonesia, has caused various environmental damage, for example the result of waste which generated from the production process. Sustainable product empowerment is a good countermeasure in handling the damage caused and for the environtment preservation. Fashion products that have a sustainable or eco design concept using natural products are a concept that is now increasingly being promoted by people in the textile andfashion from large to small scale industry. Natural color dyeing and eco printing techniques are ways that can be used to replace chemical substances in the process of dyeing and imparting patterns on natural fabrics derived from many variations of plant extracts. The experimental process of tegeran wood extract as a dye solution for the main fabric material and the tannin content in lanang leaves as a pattem and supported by mordant tunjung and alum as fixator, is a combination that we focused as a research on the effects variations when applied to rayon fabric which is starting to be used as a staple material, a substitute for pure polyester and a fabric alternative that is more accessible to people in Indonesia and has also been introduced as the main type offabric, all of which are used as a medium for materials to produce an environmentally friendly fashion product.
\end{abstract}

Keywords: eco, fashion, printing, rayon, sustainable.

\section{PENDAHULUAN}

Pertumbuhan industri fashion yang berkembang pesat di Indonesia dapat terlihat dari banyaknya kemunculan label baru dan desainer fashion muda hingga toko-toko pakaian e-commerence dengan perolehan produk melalui parbrik garmen lokal maupun impor dari negara lain khususnya market negara Cina. Beragam kegiatan yang mengusung tema fashion pun telah familiar bagi masy arakat mulai darievent lokal hingga nasional bahkan beberapa kali kerjasama internasional telah sukses dilaksanakan seperti fashion show skala internasional LA MODE Sur La Seine à Paris di Kota Paris, Perancis pada tanggal 29 September 2019 lalu oleh Indonesian Fashion Chamber (IFC) yang 
merupakan perspektif baru untuk mempromosikan karya desainer Indonesia dan menggaungkan potensi industri fashion Indonesia ke pasar global, melalui Eropa yang memiliki pengaruh besar terhadap industri fashion dunia (Mia Chitra Dinis ari. bisnis.com)

Bahkan tumbuhnya ragam pilihan bidang studi yang memfokuskan terhadap ilmu tekstil dan fashion semakin terlihat di beberapa fakultas desain universitas-universitas di Indonesia maupun pembekalan di sekolah, baik sebagai kegiatan eks trakuliku ler atau mata pelajaran tambahan. Juga atas dukungan pemerintah, Indonesia telah mampu melahirkan tren fashion nasional khususnya sektor busana mus lim hingga memiliki market internasional yang besar sekaligus mempengaruhi pertumbuhan ekonomi di Indonesia.

Pada tahun 2013 jumlah perusahaan yang bergerak di bidang fashion sudah mencapai 1.107.955 unit. Sekitar $10 \%$ dari mereka adalah peru sahaan besar, $20 \%$ adalah perusahaan menengah dan $70 \%$ adalah perusahaan kecil (Lihat UKM Indonesia: Peningkatan Dukungan Pemerintah untuk Mengatasi Tantangan). Dari 750.000 UKM yang bergerak di sektor sandang di Indonesia, sekitar $30 \%$ di antaranya adalah produsen pakaian muslim, dengan perusahaan besar menguasai $40 \%$, sedangkan us aha kecil dan menengah masing-masing menempati $30 \%$ pasar. Pada 2015, ekspor busana muslim Indonesia mencapai \$ 4,57 miliar USD atau sekitar Rp 58,5 triliun (Global Business Guide Indonesia 2016).

Namun disetiap areapertumbuhan sebuah tren terutama gaya hidup, diperlukan sebuah tanggung jawab untuk para pelakunya dalam pencegahan kemunculan efekefek negatif yang ditimbulkan terutama efeknya terhadap lingkungan. Industri pakaian dan tekstil adalah salah satu industri terbesar di dunia. Industri ini membuang bahan kimia beracun ke lingkungan, menggunakan energi y ang s angat besar dan merupakan salah satu penyumbang terbesar pemanasan global (Sas s Brown, 2010). Saat ini, pandemi Covid-19 yang melanda dunia menjadi salah satu pemicu besar akan kesadaran terhadap pelestarian lingkungan terhadap masyarakat, yang didalam penelitian ini akan difokuskan kepada dukungan untuk gerakan sustainable dan zero waste dalam indus tri teks til dan fashion. Kampanye fashion sustainable telah menjadi standar untuk menangani kontribusi industri terhadap perubahan iklim. Dampak dari kampanye fashion sustainable ini diprediksi dapat mengurangi jejak karbon dan limbah air hingga $82 \%$. Selain itu juga setiap pakaian yang digunakan kembali/ recycle
Gorga : Jurnal Seni Rupa

Volume 09 Nomor 02 Juli-Desember 2020 p-ISSN: 2301-5942 | e-ISSN: 2580-2380

memiliki umur lebih panjang dengan rata-rata hingga 2,2 tahun (Nedelcheva, Kalina. trendhunter.com.)

Para pelaku industri yang bergerak dibidang tekstil dan fashion, label dan desainer fashion besar di dunia terlihat mulai memberlakukan banyak perubahan terhad ap rancangan dan pendistribusian produk mereka sebagai respon terhadap perubahan iklim dunia. Penggunaan material alami (kain) dan teknik pengolahan tekstil berdas arkan cara dan bahan yang ramah lingkungan juga dipraktikkan ke dalam proses produksi mereka. Pewarnaan menggunakan pewama alami dari tanaman, sebagai pengganti pewarnaan zat tekstil yang menghasilkan limbah cair, dengan kandungannya yang ramah lingkungan dan lalu sisa tanaman yang diekstrak dapat diolah kembali menjadi pupuk kompos untuk regenerasi tanaman tersebut dan pemanfaatan lainnya.

Proses regenerasi juga dilakukan terhadap pengembangan serat kain, salah satunya dengan mengkombinasikan serat alam (tumbuhan) dengan polyester yang bertujuan untuk men ghasilkan material kain yang mendekati alami dan ramah lingkungan tetapi tetap durable den gan harga yang lebih terjangkau bagi mas yarakat di Indonesia. Proses ini menghasilkan material Viscose Rayon atau Kain Rayon yang juga telah banyak diproduksi di Indonesia dan dalam tahapan sosialisasi sebagai jenis kain yang dapat menjadi ciri khas kain (asal) Indonesia oleh beberapa penggerak industri tekstil nasional seperti Asosiasi Pertekstilan Indonesia (API) yang menyatakan rayon merupakan masa depan industri nasional menimbang iklim Indonesia yang sangat cocok untuk pohon bahan baku serat rayon tumbuh. Sehingga Indonesia dapat menjadi pemain utama serat rayon secara globaldengan penambahan investasi di industri rayon yang sejalan dengan strategi pendalaman s truktur industri nasional. Hal tersebut didorong oleh karakteris tik serat rayon yang sesuai dengan salah satu kriteria pendalaman produk buyer, yakni sustainable fashion, dikarenakan serat rayon berbahan baku dissolving pulp yang dapat sangat mudah diurai dalam tanah. Selain itu, serat rayon memiliki karakteris tik yang serupa dengan serat kapas (Andi M. Arief. bisnis.com).

Serat pokokyang terdapat didalammaterial kain dapat berupa serat alami maupun serat buatan. Namun bukan berarti s erat buatan tidak memiliki kelebihan tersendini terutama bagi serat campuran antara alami dan buatan yang dikombinasikan dengan harapan dapat memperoleh ragam kelebihan masing-masing didalamnya. Rayon berasal dari unsur tanaman dan zat kimia yang biasanya dikenal sebagai proses 


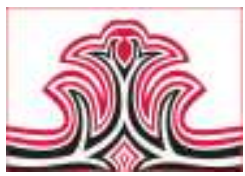

regenerated cellulosic fibres yang menghasilkan sebuah serat baru bernama Viscose Rayon dengan karakteris tik sebagai berikut(Gail Baugh. The Fashion Designer's Textile Directory: The Creative Use of Fabrics in Design):

1. Matt appearance

2. Very soft, cool hand

3. Excellent dyeability

4. Fair colourfastness (black/deep tones)

5. Good abrasion resistance

6. Very absorbent

7. No static buildup

8. Moderate cost

Pohon Kayu Tegeran atau Kayu Tegeran mempunyai nama latin Cudrania javanensis Trécul (Sinonim: Maclura javanica Blume/ C. cochinchinensis (Lour.)/ M. cochinchinensis) dan kayu kuning, merupakan tumbuhan yang tersebar luas di Asia Selatan dan Tenggara. Dalamproses membatik kayu tegeran sudah cukup familiar digunakan sebagai salah satu pewama alami namun bukan menjadi warna utama melainkan warna pelengkap/ s ekunder. Selama ini, tegeran jarang digunakan sebagai pewarna tunggal pada pembuatan batik. Biasanya, tegeran digunakan untuk warna terakhir yang tidak melalui proses pelepasan malam (lilin batik), karena mudah luntur dan warnanya kurang cerah. Maka diperlukan penelitian mengenai tegeran sebagai pewarna batik tunggal. (Vivin Atika, Irfa'ina Rohana Salma: 2017). Begitu juga dengan Daun Lanang (Oroxylum Indicum) yang lebih dikenal memiliki banyakkhasiat didalamilmu pengobatan dan dengan kandungan tanin yang cukup banyak, namun masih belum banyak yang memfokuskannya sebagai penelitian utama dalam kajian teksil dan fashion, walaupun telah banyak dipraktikkan oleh pengerajn tekstil lokal daerah dan perorangan.

Tunjung $\left(\mathrm{FeSO}_{4}\right)$ dan tawas/alum $\left(\mathrm{K}_{2} \mathrm{SO}_{4} . \mathrm{Al}_{2}\left(\mathrm{SO}_{4}\right)_{3}\right.$. $\left.24 \mathrm{H}_{2} \mathrm{O}\right)$ merupakan kandungan zat alami yang biasa dipergunakan sebagai bahan mordan dan fiks asi dalam proses pewarnaan alam yang berfungsi untuk memperkuat warna dan merubah warna alam juga mengunci warna yang telah masuk kedalam serat tergantung dari waktu pengaplikasiannya, apabila diaplikasikan diawal praktik maka disebut sebagai mordan dan apabila diakhir dianggap sebagai fiks ator.

Teknik reka tekstil pewarnaan alam dan eco printing merupakan salah satu dari sekian banyak cara yang potensial untuk mengembangkan kampanye fashion berkelanjutan. Dengan kombinasi kain rayon yang memiliki campuran material polyester dan tanaman juga eks trak kayu tegeran yang telah sering digunakan
Gorga : Jurnal Seni Rupa

Volume 09 Nomor 02 Juli-Desember 2020

p-ISSN: 2301-5942 | e-ISSN: 2580-2380

didalam proses pewarnaan batik namun jarang dijadikan sebagai bahan pewarna utama serta pemakaian daun lanang dijadikan fokus didalam penelitian ini sebagai sarana eksperimen dengan memanfaatkan material dan bahan baku yang dianggap sekunder menjadi sebuah pilihan utama dalam mendukung proses produksi produk fashion yang ramah lingkungan dalam gerakan fashion sustainable. Pengaplikasian larutan tunjung dan tawas yang ramah lingkungan juga dilakukan sebagai pendukung terciptanya hasil karya akhir yang baik.

\section{KAJIAN TEORI}

\section{Teori Fashion}

Menurut MalcomBarnard, dalam sisi etimologi dengan mengacu pada Oxford English Dictionary, kata fashion berhubungan erat dengan sebuah kata dalam Bahasa Latin yaitu factio yang memiliki arti "membuat" yang dapat di definisikan juga sebagai suatu bentuk, jenis dan tata cara atau tindakan tertentu. Tapi oleh masyarakat kontemporer di barat, fashion sering digunakan sebagai istilah dari gaya, busana dan dandanan. Namun ketika suatu gaya/tren berlalu maka bis a dikatakan sudah ketinggalan jaman dan bukan merupakan suatu bagian fashion tersebut kembali. Fashion adalah cara bagi individu maupun kelompok untuk memiliki suatu identitas tertentu juga cara bagi seseorang untuk meningkatkan status sosialnya misalkan dari gaya berpakaian yang dapat digunakan untuk menciptakan perubahan bahkan mengkritik suatu indentitas. Fashion dapat menjadi sebuah jati diri kita. (Malcolm Barnard. Fashion as Communication).

\section{1). Fashion Sustainable}

Sebuah upaya dalam mengatasi dampak lingkungan dan mencanangkan gaya hidup baru masyarakatnya khususnya para pelaku industri fashion yang telah banyak mengadopsi kampanye ini selama beberapa tahun belakangan. Is tilah fashion sustainable biasanya digunakan untuk mencakup lingkup produksi fashion atau metode desain yang ramah lingkungan dan memiliki kesadaran walaupun masih belum memiliki definisi s tandar. Sustainable sering diganti dengan kata lain, seperti 'eco', 'green' dan 'organic' (Jennifer Farley Gordon, Colleen Hill. Sustainable Fashion: Past, Present and Future) yang disisi lain program keberlanjutan ini juga berorientasi untuk mengoreksi berbagai pemahaman yang buruk akan industrifashion termasuk kekejaman terhadap hewan, kerusakan lingkungan dan eksploitasi pekerja/ buruh (Louise Lundblad, Iain A. Davies: 2015). 


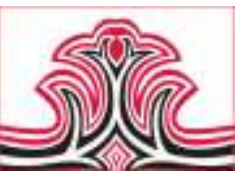

\section{Olah Reka Tekstil}

Praktik pengolahan material tekstil berupa kain atau manipulating fabric terbagi menjadi dua jenis pokok das ar yaitu surface dan structure yang dalampenelitian ini difokuskan terhadap eksplorasi material kain surface design berupa eco printing dan pewarnaan alam dengan tidak merubah struktur pada kain melainkan memberikan efek yang beragam terhadap permukaannya melalui eks plorasi motif dan warna.

\section{1). Eco Printing}

Teknik cetak alami atau eco printing yang dilakukan secara manual merupakan teknik mentransfer wama dan bentuk (Flint. Eco Color: Botanical Dyes for Beautiful Textiles) dengan cara mencetak dedaunan diatas media kertas atau kain dan memanfaatkan kandungan tanin didalamnya untuk meninggalkan sebuah motif daun yang digunakan. Ragam dedaunan dapat digunakan di dalam teknik ini, deng an perbedaan efek yang ditimbulkan tergantung daribanyaknya tanin dan perlakuannya (treatment) dengan menambahkan zat-zat lain yang dapat merangsang keluarnya tanin yang diserap oleh serat-serat kain.

\section{2). Pewarnaan Alam}

Indonesia yang kaya akan keanekaragaman sumber alam khususnya tumbuhan memiliki banyak ruang untuk bereksperimen dalammenciptakan warna-wama alam yang baru dan unik untuk sebuah material kain. Dengan hasil yang bergantung terhadap keadaan musim, intensitas hujan, udara (yang sudah tercemar polusi) dan kualitas tanah. Karakter tumbuhan yang dipilih untuk dijadikan bahan pewarnaan pun akan berpengaruh pada hasil akhir. Daun yang masih segar, sudah kering, bahkan daun yang baru jatuh pun akan memberi hasil berbeda (Flint. Eco Color: Botanical Dyes for Beautiful Textiles).

\section{METODE PENELITIAN}

Metode penelitian yang dipakai pada penelitian ini adalah kualitatif deskriptif melalui pendekatan eks perimental yang dibagi kedalam beberapa tahapan sebagai berikut:

\section{Tahap Studi Literatur}

Tahapan studi literatur mengenai sustainable fashion dan peranannya secara umumyang akan menjadi acuan studi berikutnya yaitu teknik-teknik pendukung dalam sarana pengolahan produk tekstil dan fashion (busana dan aksesoris) yang ramah lingkungan serta jenis -jenis kain yang dapat digunakan sebagai pengganti material pokok. Setelahnya studi literatur mengenai pewarnaan alam (kayu tegeran), teknik eco printing (daun lanang), zat kimia alami (tunjung dan tawas) serta pemanfaatan
Gorga : Jurnal Seni Rupa

Volume 09 Nomor 02 Juli-Desember 2020

p-ISSN: 2301-5942 | e-ISSN: 2580-2380

kain rayon yang dipilih dan diangkat menjadi topik kajian penelitian.

\section{Tahap Analisis Data Secara Deskriptif}

Proses analisis digunakan untuk menganalis is data dengan mendeskripsikan atau menggambarkan datadata yang sudah dikumpulkan sebelum lanjut kedalam proses praktik/ percobaan dalam hal ini pemaparan latar belakang, proses dan efek dari limbah dalam industri teksil dan fashion, usaha-usaha yang telah dilakukan untuk penanggulangan dan programnya di masa depan, serta pendalaman terhadap studi pengolahan reka tekstil alami dalam pembelajaran kriya tekstil khususnya di Indonesia.

\section{Tahap Eksperimen dan Desain}

Pengolahan dan perolehan data nyata yang dilaksanakan oleh peneliti dengan proses praktik percobaan teknik dan analisa hasil dalam bentuk eksperimen dilakukan sesuai dengan kerangka perancangan yang hasil akhirnya diaplikasikan pada desain produk fashion sebagai purwaru pa dengan fokus penelitian pada kayu tegeran, daun lanang, mordan tunjung, fiksator tawas dan kain rayon yang dapat mendukung penelitian selanjutnya.

\section{Tahap Pemaparan dan Kesimpulan}

Merupakan tahapan penjelasan dan kesimpulan dari data yang dihasilkan dari eksperimen penelitian yang diwujudkan ke dalam sebuah produk fashion berdasarkan dari tahapan yang telah dilakukan sebelumnya.

\section{HASIL DAN PEMBAHASAN}

\section{Hasil}

\section{1). Tahap Eksperimen}

Dalam pelaks anaannya dilakukan proses uji coba dengan tahapan sebagai berikut:

\section{(1). Persiapan Kain}

\section{a. Pre-Mordan}

Kain rayon melalui proses pembersihan dengan cara direndam/ dibasuh menggunakan TRO (Turkish Redd Oil) yaitu salah satu bahan pelengkap berbentuk serbuk putih seperti deterjen atau dapat langsung menggunakan deterjen (namun TRO dipilih untuk mendapatkan hasil yang lebih maksimal) yang berfungsi untuk menghilangkan kotoran dan membuka serat kain agar dapat menyerap warna saat dilakukan proses eco printing maupun pewarnaan. Proses perendaman dapat dilakukan semalaman atau lebih sesuai dengan kebutuhan. Setelah dilakukan perendaman, kain langsung dibilas dengan air dan dijemur. Dalamekperimen ini digunakan 20 gramTRO untuk 1 liter air hangat. 


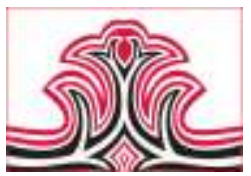

b. Mordan

Mordan direbus di dalam panci berisi air hingga mendidih lalu disiramkan ke atas kain atau juga kain dapat direbus bersamaan dengan larutan mordan hingga mendidih, tiriskan dan ratakan hingga kain terendam dengan rata. Rendam kain semalaman dan setelahnya dijemur tanpa diperas, perlu diingat bahwa kain harus tetap dalamkeadaan lembab sebelum dilakukan proses eco printing, proses penjemuran gunanya untuk menetes kan sisa air rendaman hingga kain tidak terlalu bas ah. Eks perimen ini menggunakan 20 gram tunjung untuk 1 liter air hangat.
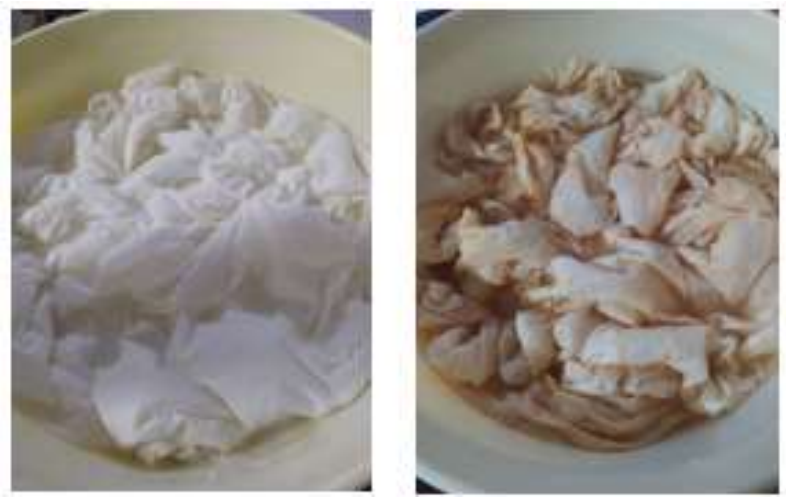

Gambar 1. Perubahan Warna pada Kain Rayon Saat Direndam TRO (Kiri) dan Tunjung (Kanan) (Sumber: Aulia Wara Arimbi Putri, 2020)

\section{(2). Treatment Daun}

Dalam persiapannya beragam jenis daun yang akan digunakan pada proses eco printing baiknya melewati perlakuan khusus terlebih dahulu, bagi daun yang memiliki tanin yang tidak banyak, dapat dipancing dengan merendamnya didalam tunjung atau tawas, namun untuk daun yang memiliki tanin yang banyak cukup merendamnya dengan air selama dua jam atau lebih. Disini daun lanang mendapatkan treatment rendaman air selama lebih dari dua jam setelah dibersihkan terlebih dahulu dari kotoran yang menempel. Sisa air rendaman akan tampak keruh setelah digunakan, yang menandakan zat tanin didalamnya telah keluar melalui pori-pori daun. Sebaiknya daun yang telah direndam dilap perlahan menggunakan lap kain sebelum diletakkan ke media kain rayon, daun dan kain yang lembab menghasilkan pentransferan warna yang lebih baik.
Gorga : Jurnal Seni Rupa

Volume 09 Nomor 02 Juli-Desember 2020 p-ISSN: 2301-5942 | e-ISSN: 2580-2380

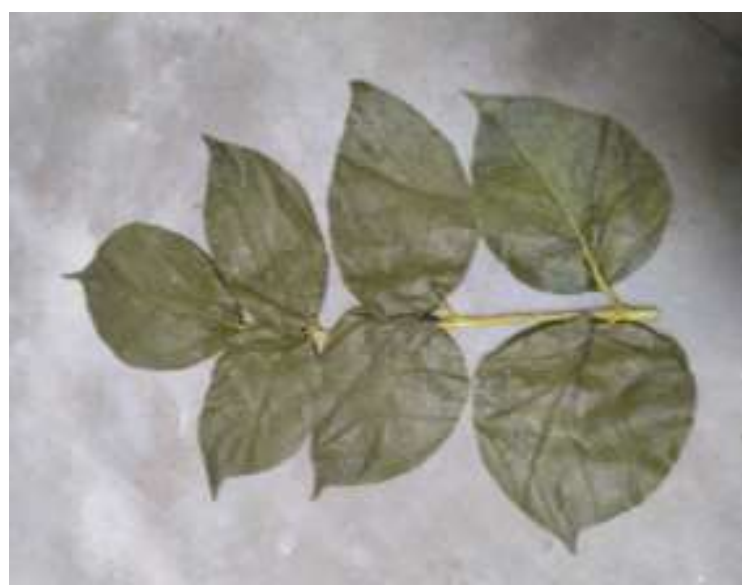

Gambar 2. Hasil Rendaman Daun Lanang (Sumber: Aulia Wara Arimbi Putri, 2020)

\section{(3). Proses Eco-Printing}

Kain rayon yang telah direndamtunjung dibentangkan di atas meja/ lantai yang telah dibersihkan dan dialasi dengan koran bekas. Ratakan kain hingga tidak ada yang berkerut, gunanya agar mendapatkan hasil cetakan daun yang menyatu. Setelahnya dimulai proses peletakan daun yang telah direndam air keatas permukaan kain satu per satu, motif dapat disesuaikan dengan keinginan atau jugadapat dis usun secara acak.

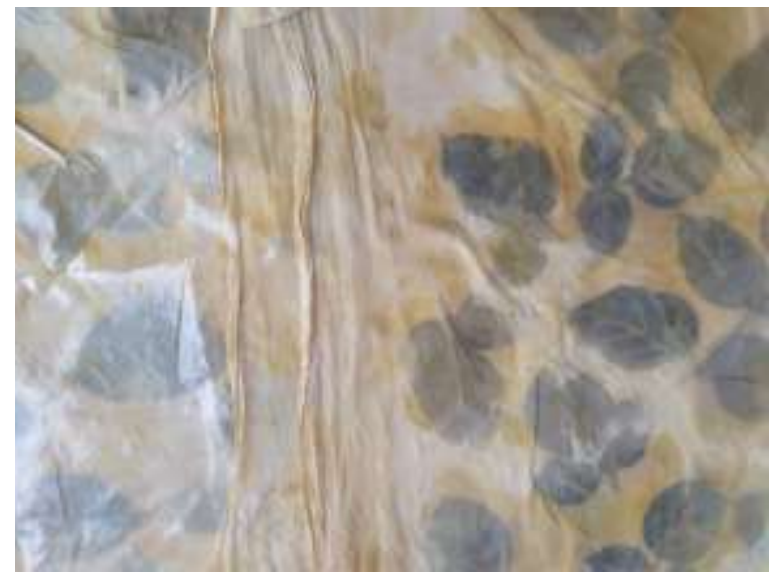

Gambar 3. Proses Eco Printing dengan Kain yang Telah Dilapisi Plastik untuk Persiapan Mengukus

(Sumber: Aulia Wara Arimbi Putri, 2020)

Setelahnya permukaan kain y ang telah ditutupi dengan daun dapat ditutupi dengan "kain selimut" (kain berbahan dasar sama yang juga telah direndammordan) gunanya untuk menahan gerakan daun ketika diikat dan dikukus. Dalameks perimen ini kain dibagi menjadi dua sisi, satu sisi yang diberikan daun dan sisi lainnya berfungsi sebagai selimut, dengan tujuan untuk mendapatkan motif yang berpantulan (mirror). Lapisi dengan plastik untuk menahan rembes an warna yang keluar dari daun (plas tik dapat digunakan berkali-kali) lalu gulung kain dan ikat dengan ikatan yang mudah 


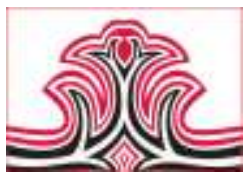

untuk dibuka agar tali dapat dipergunakan kembali. Tali dapat menggunakan tali kasur atau rapia.

\section{(4). Pengekstrakan Tanin Daun Lanang dan Kayu} Tegeran

Disini digunakan cara two in one untuk menghemat penggunaan gas dan waktu pengerjaan yaitu dengan menggunakan dua area di dalamklakat/media kukusan dengan durasi selama dua jam, sebagaimana yang ditunjukkan di dalam gambar berikut:

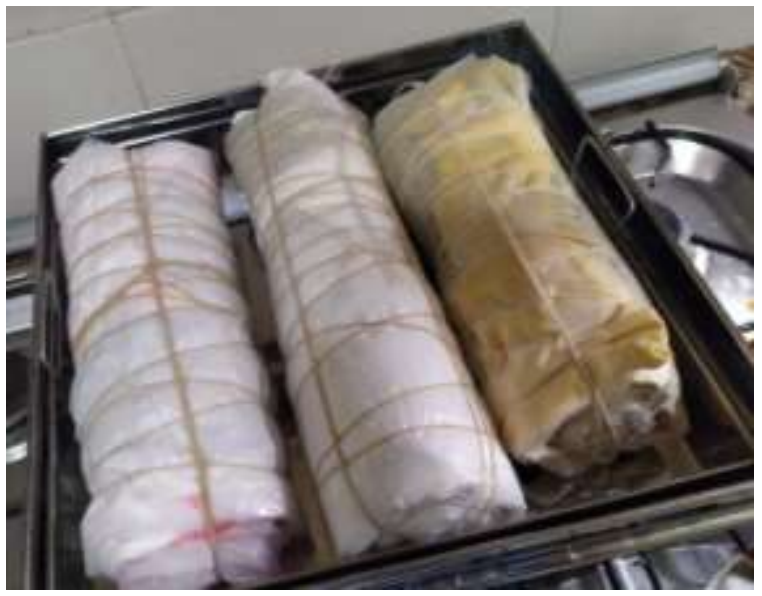

Gambar 4. Bagian Atas (Tatakan) Digunakan untuk Mengukus Kain Rayon Berisi Daun Lanang (Sumber: Aulia Wara Arimbi Putri, 2020)

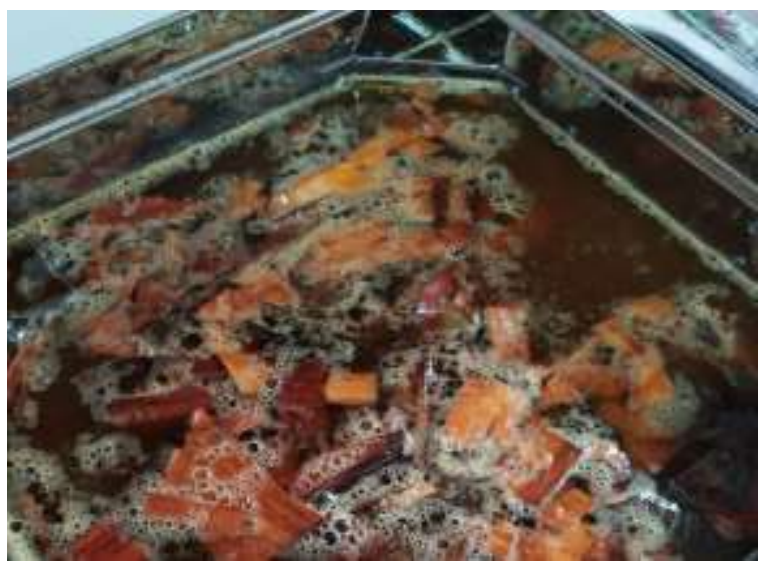

Gambar 5. Bagian Bawah (Tempat Air) Digunakan untuk Mengekstrak Kayu Tegeran dengan Cara Direbus (Sumber: Aulia Wara Arimbi Putri, 2020)

Dalam proses pengekstrakan meng gunakan tig a liter air untuk 500 gram kayu tegeran yang direbus hingga mendapatkan 1,5 liter air atau apabila ingin mendapatkan warna lebih pekat dapat ditunggu hingga 0,75 liter dan seterusnya.
Gorga : Jurnal Seni Rupa

Volume 09 Nomor 02 Juli-Desember 2020 p-ISSN: 2301-5942 | e-ISSN: 2580-2380

\section{(5). Pencelupan Warna Alam}

Kain rayon yang telah dikukus lalu dibuka untuk melihat hasil eco printing yang didapatkan, sambil mempersiapkan proses pencelupan, sisa daun yang masih menempel di kain dibersihkan. Proses pencelupan dapat dilakukan sesuai dengan kepekatan warna yang di inginkan, apabila ingin lebih pekat, setelah dijemur dapat dilakukan pencelupan kembali dan seterusnya. Dalameks perimen ini hanyadilakukan satu kali pencelupan saja dan langsung dijemur tanpa diperas.

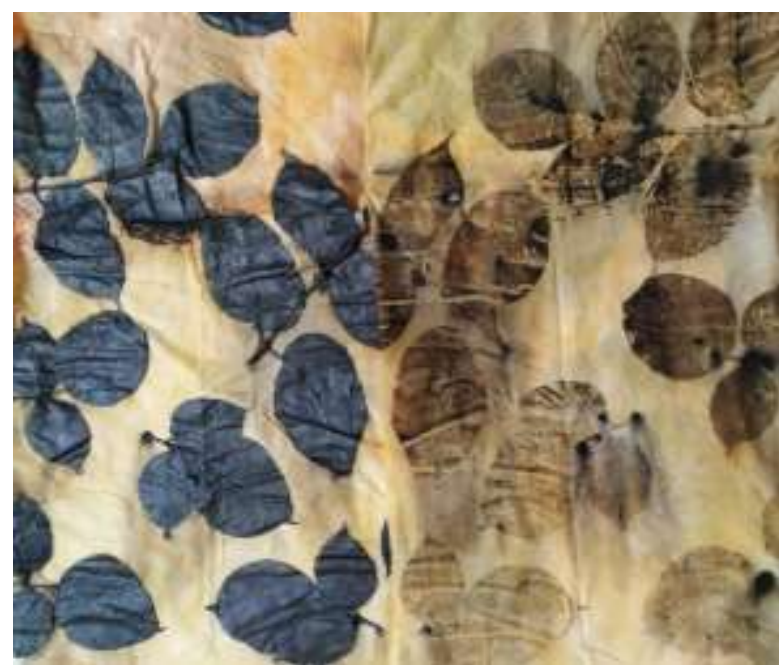

Gambar 6. Hasil dari Eco Printing dengan Perbandingan Daun Asli (Kiri) dan Hasil Cetaknya (Kanan) (Sumber: Aulia Wara Arimbi Putri, 2020)

\section{(6). Proses Fiksasi dan Pembilasan}

Setelah kain dijemur sampai air berhenti menetes maka dilakukanlah proses fikasi dengan merendamya didalam larutan 20 gram tawas untuk 1 liter air hangat selama kurang lebih 10 menit, lalu kain pun dijemur kembali hingga kering dan dibilas hingga air sisa bilasan jernih. Disini proses pembilasan dilakukan sampai tiga kali sesi, sesi pertama dan kedua dibilas hanya dengan air dan dijemur lalu sesi ketiga dibilas dengan menggunakan deterjen (dicuci tanpa mesin) gunanya untuk menghilangkan bau yang ditimbulkan oleh daun lanang dan tunjung, sehingga kain dapat layak pakai untuk diproduksi menjadi sebuah produk.

Dalam eksperimen ini diperoleh hasil perbandingan efek warna kain yang berasal dari treatment yang berbeda-beda disetiap prosesnya yang dalampenelitian ini hanya difokuskan kedalam beberapa treatment tertentu, namun tidak menutup kemungkinan bahwa dari penelitian yang sudah dikerjakan dapat dikembangkan kembali untuk mendapatkan hasil yang lebih beragam seperti penambahan banyaknya zat 


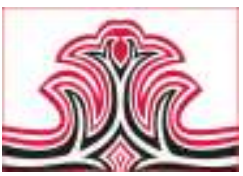

tunjung dan tawas, atau perbedaan antara lamanya proses pengukusan dan penjemuran dan lainnya yang dapat menjadi topik penelitian selanjutnya.

Tabel 1. Proses Eksperimen Mendapatkan Hasil Perubahan Warna yang Ditimbukan Melalui Beberapa Tahapan Proses

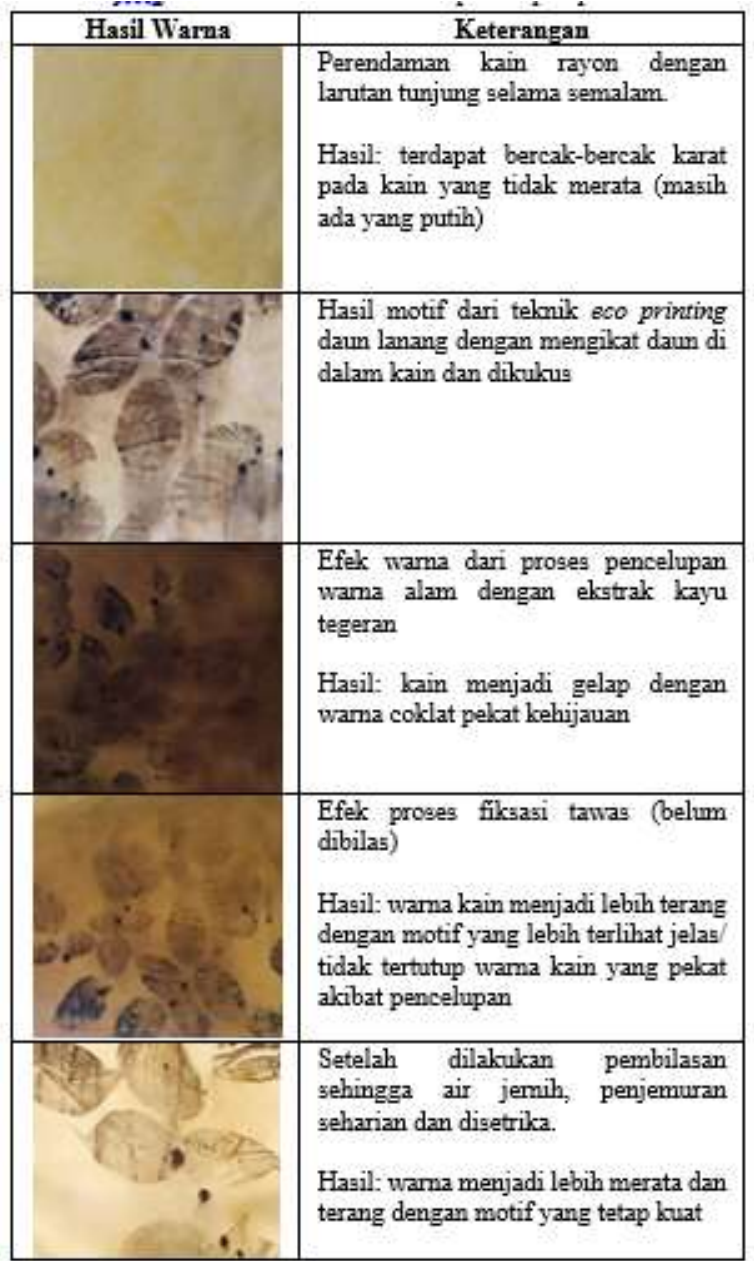

\section{Pembahasan}

Hasil yang didapatkan dari proses uji coba ini dapat dilihat pada perubahan warna yang pada mulanya bias menjadi pekat dan akhirnya terang.

Pengamatan yang dilakukan bahwa mordan tunjung memiliki unsur zat kimia besi yang dapat merubah warna kain putih menjadi memiliki bercak-bercak s eperti tertempel besi berkarat y ang tidak merata, selain warna, tunjung juga memberikan bau besi pada kain yang sedikit mencolok sehingga perlu dilakukan pencucian secara seksama agar kain layak untuk dikenakan.

Merebus kain guna mengeluarkan tanin daun membuat kandungan tunjung pada kain terkonsentrasi pada daun, sehingga warna kain mulai merata dan pucat dibandingkan dengan warna hitam pada kain yang diletakkan daun
Gorga : Jurnal Seni Rupa

Volume 09 Nomor 02 Juli-Desember 2020

p-ISSN: 2301-5942 | e-ISSN: 2580-2380

Pemberian ekstrak kayu tegeran pada kain yang memiliki kandungan tunjung menimbulkan reaksi yang s angat cepat, dengan warna ekstrak kayu yang awalnya jinga (orange) langsung menghitam ketika dicelupkan kain tersebut dan menimbulkan warna kain menjadi gelap hampir hitam kehijauan hingga menutupi motif daun yang telah dihasilkan.

Namun warna kain menjadi kembali pulih ketika fiks asi tawas dilakukan dan makin terang ketika mulai dilakukan penjemuran dan pembilas an secaraberulangulang. Tetapi proses terakhir inibukan berarti membuat warna menjadi hilang, melainkan merata dengan motif daun yang mas ih kuat (gambar jelas dapat dilihat pada foto produk).

\section{KESIMPULAN DAN SARAN}

\section{Kesimpulan}

Pengeksplorasian teknik eco printing dan pewamaan alam pada kain ray on dapat dijadikan sebag ai alternatif pengolahan material kain sebagai das ar produk fashion yang ramah lingkungan. Penyerapan warna yang beras al dari tanin daun lanang dan eks trak kayu tegeran dapat diserap dengan baik oleh kain rayon sehingga dapat memberikan variasi yang beragam dan unik, dikarenakan motif daun yang ditimbulkan tidak ada yang sama disetiap produksinya. Uji coba daya tahan dari proses penjemuran dan pencucian pun tidak menurunkan kualitas warna, motif dan kekuatan kainnya sehingga bisa menjadi material kain yang layak pakai untuk perancangan sebuah produkfashion, khususnya busana, yang menarik dan memiliki nilai jual. Dengan sifat kain rayon yang dingin dan lembut dan zat pewarnaalam, kombinasi ini dinilai sangat baik untuk diterapkan dalam proses produksi tekstil dan fashion yang berkelanjutan di masa kini. 

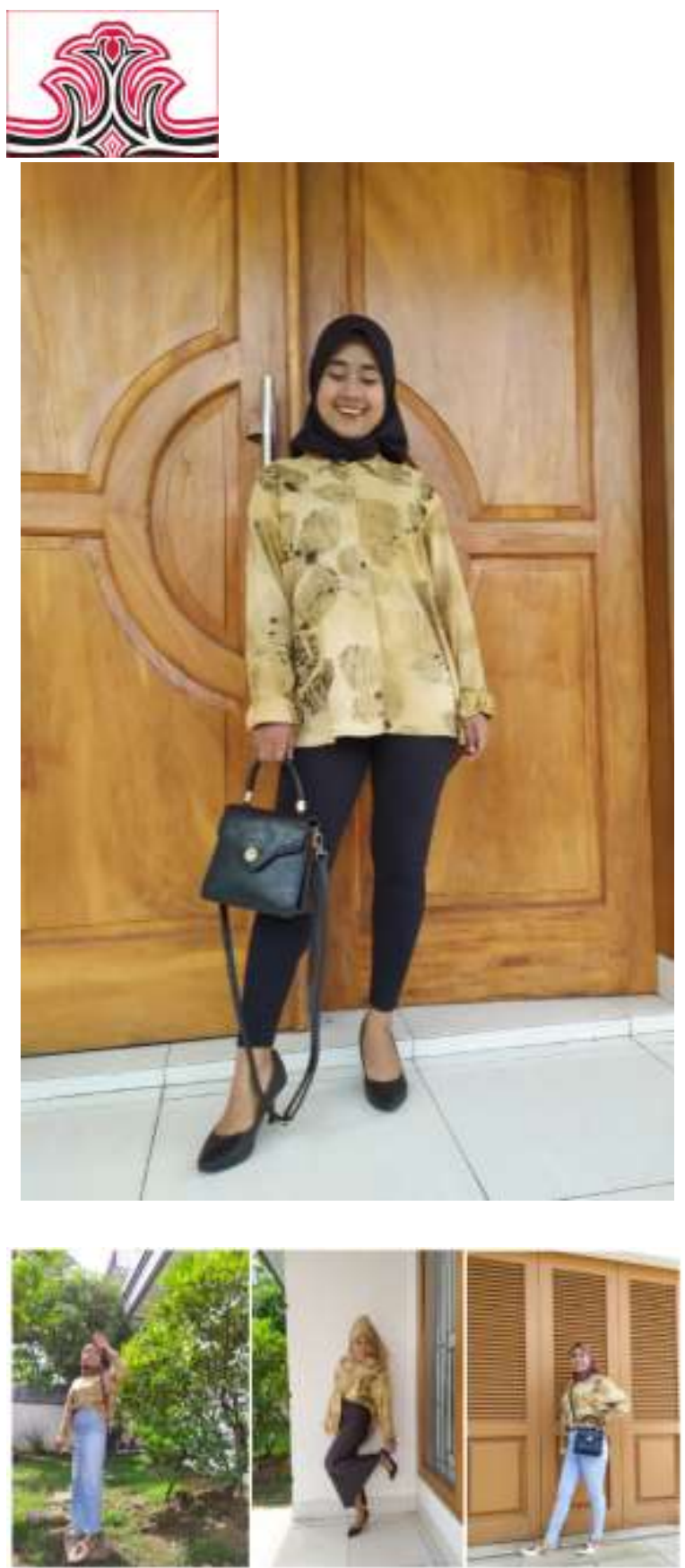

Gambar 7. Produk Kemeja Ready to Wear Berbahan Dasar Kain Rayon dengan Teknik Eco Printing dan Pewarnaan Alam (Sumber: Aulia Wara Arimbi Putri, 2020)

Hasil produkfashion yang dihasilkan dalampenelitian ini berupa kemeja lengan panjang yang dapat digunakan dalam kegiatan kasual maupun formal, desain motif dan warna yang menarik membuatnya mudah untuk di padupadankan dengan berbagai jenis produkfashion lainn ya sesuai deng an okasi si pemakai.

\section{Saran}

Penelitian yang dilangsungkan sebagai dasar upaya dukung an terhadap kampanye sustainable fashion atau zero waste fashion dengan memfokuskan terhadap potensi penggunaan kain rayon sebagai material mentah utama yang diolah kembali dengan teknik eco printing dan pewarnaan alam ini merupakan satu dari beragamcara yang masih dapat dikembangkan kembali untuk mendukung kelangsungan kampanye tersebut,
Gorga : Jurnal Seni Rupa

Volume 09 Nomor 02 Juli-Desember 2020 p-ISSN: 2301-5942 | e-ISSN: 2580-2380

ragam eksplorasi dalamproses ekperimen mas ih dapat terus dilakukan untuk mendapatkan hasil yang lebih bervariasi dan menarik. Pemerintah pula dapat memberikan banyak program dalam mendukung kegiatan sustainability di berbagai bidang, khususnya dalam indus tri teks til dan fashion dengan mengadakan sosialisasi berupa workshop yang dapat diikuti oleh mas yarakat umum baik yang bergelut didalam bidang tekstil, garmen dan fashion dan yang memiliki ketertarikan dan mendukung manfaat dari programini. Hal tersebut juga dapat dihibahkan kepada fakultas/ program studi kriya tekstil dan fashion di Indonesia untuk menjadi pilar dalam menjalankan program tersebut sebag ai wujud pengabdian kepada mas yarakat.

\section{DAFTAR RUJUKAN}

Arief, A. M. (2020). API: Rayon adalah Bahan Baku Masa Depan Industri TPT. Diunduh pada 9 Juli 2020 [Online]. Di

https://ekonomi.bisnis.com/read/20200221/2 57/1204420/api-rayon-adalah-bahan-bakumasa-depan-industri-tpt.

Atika, V., \& Salma, I.R. (2017). Kualitas

Pewarnaan Ekstrak Kayu Tegeran (Cudrania Javenesis) padaBatik. Ejournal Kemenprin, 34.(1), 11-18.

Barnard, M. (2002). Fashion as Communication. 2nd Edition.. Oxfords hire: Routledge.

Baugh, G. (2018). The Fashion Designer's Textile Directory: The Creative Use of Fabrics in Design. London: Thames \& Hudson Ltd .

Brown, S. (2010). Eco Fashion. 1st Edition. London: Laurence King Publishing.

Dinis ari, M. C. (2019). 18 Desainer Indonesia akan Tampil di La Mode Sur La Seine Paris. Diunduh pada 2 September 2020 [Online]. Di https://ifestyle.bis nis.com/read/20190922/10 4/1151051/18-desainer-indonesia-akantampil-di-la-mode-sur-la-s eine-paris .

Flint, I. (2008). Eco Color: Botanical Dyes for

Beautiful Textiles. United Stated: Interwave Press Inc.

Global Business Guide Indonesia. (2016). Indonesia Aiming to be the Islamic Fashion Capital by 2020. Diakses 28 Juni 2020 (Online). Di http://www.gbgindonesia.com/en/manufactur ing/article/2016/indonesia_aiming_to_be_the _islamic_fashion_capital_by_2020_11646.

Gordon, J. F., \& Colleen, H. (2014). Sustainable

Fashion: Past, Present and Future. London: Blooms bury Visual Art.

Lundblad, L., \& Davies, I., A. (2014). The Values 
and Motivations Behind Sustainable Fashion Consumption. Journal of Consumer

Behaviour. 44(3), 309-323.

Nedelcheva, K. (2019). Upcycled Sustainable

Fashion Campaign. Diunduh pada 10

Agustus 2020 [Online]. Di

https://www.trendhunter.com/trends/sustaina ble-fashion-campaign. 